\title{
IMPLEMENTASI ALGORITMA NAÏVE BAYES MENGGUNAKAN ISEAR UNTUK KLASIFIKASI EMOSI LIRIK LAGU BERBAHASA INGGRIS
}

\author{
Laksmita Widya Astuti ${ }^{1 *}$, Antonius Rachmat C. ${ }^{1}$, Yuan Lukito ${ }^{1}$ \\ Jurusan Teknik Informatika, Fakultas Teknologi Informasi, Universitas Kristen Duta Wacana \\ Jl. Dr. Wahidin Sudiro Husodo No. 5-25, Yogyakarta 55224 \\ E-mail: laksmita.widya@ti.ukdw.ac.id, anton@ti.ukdw.ac.id, yuanlukito@ti.ukdw.ac.id \\ Korespondensi penulis
}

\begin{abstract}
Abstrak: Lirik lagu merupakan suatu ungkapan perasaan seseorang terhadap sesuatu hal yang sudah dilihat, didengar maupun dialaminya sehingga tidak jarang emosi menjadi salah satu kriteria user dalam melakukan pencarian. Pencarian lirik melekat pada kategori yang tidak hanya terbatas berdasarkan genre atau judul lagu, namun juga melalui emosi dari lirik lagu yang diungkapkan. Agar dapat mencapai tujuan tersebut, diperlukan suatu sistem pengkategori yang mengenali lirik lagu secara otomatis dengan salah satu metode klasifikasi yaitu Naïve Bayes. Faktor yang mendorong tingginya tingkat akurasi bukan hanya terletak pada metode klasifikasi saja, namun proses sebelum menuju tahap klasifikasi juga berpengaruh pada hasil yang didapatkan. Maka dari itu, penulis melakukan penelitian melalui beberapa tahap yaitu preprocessing berupa tokenisasi, stopword dan stemming, kemudian feature selection yang digunakan adalah TF-IDF dengan bantuan ISEAR karena mengandung 7 emosi dasar. Dari ketujuh emosi dasar tersebut, tiga diantaranya merupkan emosi yang akan digunakan dalam penelitian ini yaitu anger, sadness dan joy. Hasil dari penelitian ini menunjukkan dengan menggunakan ISEAR akurasi tertinggi terdapat pada feature set $60 \%$ dan $100 \%$ yaitu sebesar $82,2 \%$. Perbedaan signifikan dihasilkan pada penggunaan ISEAR dengan akurasi rata-rata keseluruhan porsi featureset sebesar 77\% sedangkan tanpa menggunakan ISEAR rata-rata akurasi sebesar 53\%. Dokumen paling relevan untuk pengujian menggunakan ISEAR terdapat pada kategori angry dengan rata-rata $f$-measure sebesar 0.7267 .
\end{abstract}

Kata kunci: ISEAR, tf-idf, Naïve Bayes, Emosi, Lirik Lagu

\begin{abstract}
Song lyric is an expression of one's feelings about something that has been seen, heard and experienced; therefore, emotion is not uncommon things for the user to be used as one of the criteria in song discovery. Searching for lyrics is close to a category that is not only limited to genres or song titles, but it can also be done through the emotions disclosed by the lyrics. In order to achieve these objectives, we build song lyrics classification based on Naïve Bayes classification method. The factors that promote high levels of accuracy do not only lie in the method of classification; as a matter of fact, the pre-proceeding stage for classification process also affects the results obtained. Therefore, we conducted research through several stages; pre-processing such as tokenization, stop word processing and stemming. The feature selection used is TF-IDF with the help of ISEAR because it contains seven basic emotions. Out of the seven basic emotions, three of them that denote emotions used in this research are anger, sadness and joy. The results of this research demonstrate that by using ISEAR, the highest accuracy occurs at $60 \%$ and $100 \%$ of the feature set is by $82.2 \%$. The significant difference resulting in the use of ISEAR with the overall average accuracy of feature set portion is 77\%; whereas, without using ISEAR, the average accuracy is around 53\%. The most relevant document for testing using ISEAR falls under the emotion category of anger, with the average $F$ measure of 0.7267 .
\end{abstract}

Keywords: ISEAR, tf-idf, Nä̈ve Bayes, Mood, Song Lyrics

\section{PENDAHULUAN}

Musik memiliki peran yang penting bagi kehidupan manusia. Selain sebagai media hiburan, musik juga merupakan media bantu diri untuk menangani perasaan emosi yang sedang di hadapi (Lerik \& Prawitasari, 2005). Banyak orang salah mengartikan bahwa lagu-lagu yang memiliki irama bersemangat seperti rock, dangdut, dan country menggambarkan lagu yang ceria dan penuh kegembiraan, sedangkan lagu mellow seperti jazz, pop, dan ballad menggambarkan makna lagu yang sedih karena memiliki irama yang lambat. Setiap bait pada lirik lagu umumnya mengandung maksud melalui gaya bahasa yang digunakan oleh pengarang. Pengarang bebas menyampaikan emosi dengan genre yang bervariasi sesuai dengan keinginannya. Pengungkapan emosi tersebut tidak jarang menjadi salah satu kebutuhan umum para penikmat musik, sehingga pemilihan kategori dalam pencarian lagu tidak hanya terbatas berdasarkan genre, namun juga melalui emosi dari para pencipta lagu.

Pemilihan lirik lagu terutama saat user melakukan sebuah pencarian melekat dengan sebuah kategori agar lebih mudah dan terstruktur. Agar dapat mencapai tujuan tersebut, diperlukan mesin pengkategori 
agar lirik lagu dapat diklasifikasikan secara otomatis. Mesin kategori lirik lagu berdasarkan emosinya dapat dibuat dengan menggunakan banyak algoritma, salah satunya adalah Naïve Bayes. Algoritma ini dipilih karena memiliki kinerja yang cukup tinggi untuk klasifikasi dokumen teks (Hamzah, 2012).

Tidak cukup menggunakan algoritma klasifikasi supaya lirik lagu dikategorikan tepat sesuai emosinya, namun penggunaan feature set ISEAR juga akan di terapkan di dalam penelitian ini. Feature set ISEAR dapat di unduh dari http://www.affective-sciences.org/ researchmaterial. Tujuan dari penggunaan feature set ISEAR ini di maksudkan agar hasil klasifikasi yang dihasilkan semakin baik. Pengukuran akurasi dilakukan dengan membandingkan perhitungan akurasi sistem, precision, recall dan f-meassure baik menggunakan feature set ISEAR maupun tidak menggunakan data ISEAR. Porsi feature set yang digunakan beranekaragam yaitu 10\%, 30\%, 60\% dan $100 \%$ dari total term terbaik yang sudah melalui proses feature selection.

\section{METODE PENELITIAN}

\section{Langkah Penelitian}

Penelitian ini dilakukan dengan melakukan 2 proses utama yaitu pengumpulan data dan proses kinerja sistem. Pengumpulan data dilakukan melalui 2 cara yaitu labeling dan pengambilan sampel lirik lagu. Proses klasifikasi dilakukan dengan menggunakan 3 kategori emosi yang terdapat pada ISEAR yaitu happy, angry dan sad. Ketiga emosi tersebut dipilih karena merupakan emosi yang paling mudah dibangkitkan oleh musik. Input dari sistem berupa dokumen lirik lagu yang kemudian dilakukan proses preprocessing, feature selection, klasifikasi dan yang terakhir adalah evaluasi. Output dari sistem berupa hasil evaluasi dan hasil klasifikasi. Proses preprocesssing dilakukan dengan menggunakan tokenisasi, stopword dan stemming. Feature selection dilakukan dengan melakukan perhitungan bobot tf-idf. Jika terdapat pada ISEAR, maka bobot dikalikan 10 sehingga lebih dominan. Sedangkan klasifikasi dapat dilakukan dengan menggunakan metode Naïve Bayes. Dari hasil yang didapatkan, dilanjutkan dengan menghitung evaluasi. Hasil evaluasi dapat dihitung dengan menggunakan rumus akurasi, precsion, recall dan $f$-measure.

\section{Dasar Teori}

\section{Emosi dan Musik}

Emosi dapat digambarkan sebagai keadaan yang pada umumnya disebabkan oleh suatu kejadian penting sebuah subyek. Banyak pskologi dari berbagai dunia yang menjadikan emosi sebagai objek penelitian. (Oatley \& Jenkins, 1996) mendefinisikan emosi sebagai:

1. Keadaan mental sadar yang dinyatakan dengan kemampuan mengenali,

2. Kualitas perasaan dan diarah untuk beberapa subyek,

3. Gangguan jasmani pada beberapa organ tubuh,

4. Pengenalan ekspresi pada wajah, suara dan isyarat tubuh,

5. Kesiapan untuk melakukan tindakan tertentu.

Musik diyakini oleh para peneliti dapat memunculkan emosi. Koelsch (2005) dalam (Sakti, 2010), mengemukakan bahwa proses musik memunculkan emosi terkait dengan otak manusia. Dia menyimpulkan bahwa musik dapat memunculkan emosi secara cukup konsisten pada semua subyek. Orang menggunakan musik untuk mengubah emosi, untuk melepaskan emosi, untuk mencocokkan emosi mereka saat ini, untuk menikmati atau menghibur diri, dan untuk mengurangi stres (Behne, 1997; Juslin dan Laukka, 2004; Sloboda dan O'Neill, 2001; Zillman dan Gan, 1997) dalam (Sakti, 2010).

Penelitian mengenai musik dan emosi dimulai oleh Hevner (1936) dalam dalam (Sakti, 2010). Dia melakukan penelitian mengenai musik dan emosi. Dalam eksperimennya, peneliti meminta subyek penelitian menuliskan sebuah kata sifat yang hadir dalam pikirannya saat musik dimainkan. Dari penelitian tersebut, Hevner (1936) dalam dalam (Sakti, 2010) berpendapat bahwa musik membawa sebuah arti emosi.

\section{Tokenisasi}

Tokenisasi adalah sebuah proses yang dilakukan untuk memotong atau memecah kalimat menjadi beberapa bagian atau kata (Manning, Raghavan, \& Schütze, 2008). Proses tokenisasi memisahkan suatu rangkaian karakter berdasarkan karakter spasi, dan mungkin pada waktu yang bersamaan dilakukan juga proses penghapusan karakter tertentu, seperti tanda baca. Token seringkali disebut sebagai istilah (term) atau kata, sebagai contoh sebuah token merupakan suatu urutan karakter dari dokumen tertentu yang dikelompokkan sebagai unit semantik yang berguna untuk diproses.

\section{Stopword}

Stopwords removal adalah sebuah proses untuk menghilangkan kata yang 'tidak relevan' pada hasil parsing sebuah dokumen teks dengan cara membandingkannya dengan Stoplist yang ada Kata-kata yang terlalu sering muncul dalam dokumen-dokumen 
belum tentu berguna dalam proses retrieval. Kata-kata yang tidak berguna nantinya akan dibuang dan tidak dijadikan index term.

\section{Stemming}

Stemming merupakan proses untuk mentransformasi kata-kata yang terdapat dalam suatu dokumen ke kata-kata akarnya (root word) dengan menggunakan aturan-aturan tertentu. Sebagai contoh pada dokumen bahasa inggris, kata dasar stem dapat membentuk kata "stems", "stemmer", "stemming", "stemmed". Adapun langkah-langkah algoritma porter dapat dilihat pada Gambar 1.

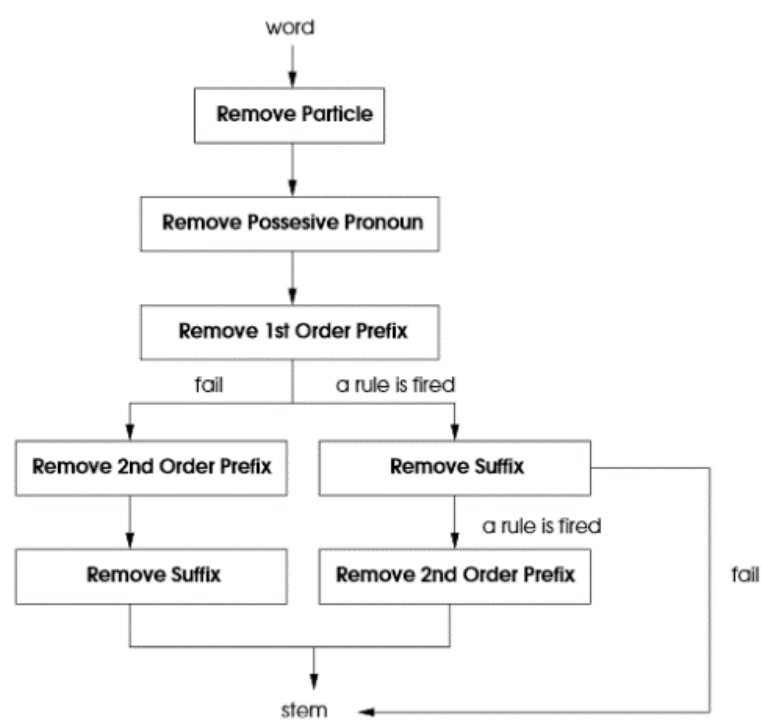

Gambar 1. Algoritma porter (Tala, 1999)

\section{Pembobotan TF-IDF}

Tf-Idf adalah perhitungan yang menggambarkan seberapa pentingnya kata (term) dalam sebuah dokumen dan korpus. Proses ini digunakan untuk menilai bobot relevansi term dari sebuah dokumen terhadap seluruh dokumen dalam korpus. Menurut Manning, Raghavan, \& Schütze (2008), rumus bobot TF-IDF di jabarkan pada poin 1 dan 2, sebagai berikut:

$$
\begin{aligned}
& \operatorname{IDF}(\mathbf{w})=\log \left(\frac{\mathbf{N}}{\operatorname{DF}(w)}\right) \\
& \operatorname{ITF}-\operatorname{IDF}(\mathbf{w})=\operatorname{TF}(\mathbf{w}, \mathbf{d}) \times \operatorname{IDF}(\mathbf{w})
\end{aligned}
$$

Keterangan:

TF-IDF $(\mathrm{w}, \mathrm{d})=$ bobot suatu kata dalam keseluruhan dokumen

$\mathrm{W}=$ word

$\mathrm{d}=$ dokumen

$\mathrm{TF}(\mathrm{w}, \mathrm{d}) \quad=$ frekuensi kemunculan kata $\mathrm{w}$ dalam dokumen d

$\mathrm{IDF}(\mathrm{w}) \quad=$ inverse $\mathrm{DF}$ dari kata $\mathrm{w}$

$\mathrm{N} \quad=$ jumlah keseluruhan dokumen

$\mathrm{DF}(\mathrm{w}) \quad=$ jumlah dokumen yang mengandung kata w
ISEAR

Isear merupakan dataset yang sudah diberi label sesuai dengan 7 emosi dasar hasil penelitian. Berasal dari 16 negara lintas lima benua, penelitian ISEAR tidak ditujukan pada klasifikasi teks namun mencoba mencari hubungan antara emosi dan perbedaaan budaya, gender, umur dan agama (Scherer \& Wallbott, 1986). Dataset tujuh jenis emosi yaitu jijik, malu, marah, sedih, senang, bersalah dan takut (Destuardi \& Sumpeno, 2009). Data ISEAR dapat dilihat dari situs: http://www.affective-sciences.org/ researchmaterial.

\section{Naïve Bayes}

Teorema Naïve Bayes adalah teorema yang digunakan dalam statistika untuk menghitung peluang untuk suatu hipotesis. Berdasarkan (Manning, Raghavan, \& Schütze, 2008) persamaannya dijabarkan pada rumus 3 , sebagai berikut:

$$
\begin{aligned}
& \boldsymbol{C}_{\text {MAP }} \propto \\
& \underset{\boldsymbol{C}_{j \in C} C}{\arg \max } \Pi_{i=1}^{n} P\left(\boldsymbol{t}_{i} \mid \boldsymbol{C} j\right) P(C j)
\end{aligned}
$$

Keterangan:

$\mathrm{Cj} \quad=$ Kategori emosi (dalam penelitian ini $\mathrm{j}=$ kategori emosi happy, sad, dan angry).

$\mathrm{P}(\mathrm{ti} \mid \mathrm{Cj})=$ Probabilitas ti pada kategori $\mathrm{Cj}$

$\mathrm{P}(\mathrm{Cj})=$ Probabilitas dari $\mathrm{Cj}$

Untuk $\mathrm{P}(\mathrm{Cj})$ dan $\mathrm{P}(\mathrm{ti} \mid \mathrm{Cj})$ dihitung pada saat pelatihan dimana persamaannya dapat dilihat pada rumus 4 dan 5 sebagai berikut:

$\boldsymbol{P}\left(\boldsymbol{C}_{\boldsymbol{j}}\right)=\frac{\boldsymbol{N}_{\boldsymbol{c}}}{\boldsymbol{N}^{\prime}}$

$P\left(t_{i} \mid C_{j}\right)=\frac{N_{t}+1}{N t c+N t c^{\prime}}$

Keterangan:

$\mathrm{Nc}=$ jumlah dokumen setiap kategori $\mathrm{j}$

$\mathrm{N}^{\prime}=$ jumlah dokumen dari semua kategori

$\mathrm{Nt}=$ jumlah frekuensi kemunculan setiap kata

$\mathrm{Ntc}=$ jumlah frekuensi kemunculan kata dari setiap kategori

Ntc' = jumlah semua kata dari semua kategori

\section{Pengukuran Akurasi}

Pengukuran akurasi yang digunakan dengan menghitung precision, recall, $f$-measure dan akurasi sistem dalam mengklasifikasikan dokumen. Recall adalah jumlah dokumen yang terklasifikasi dengan benar oleh sistem dibagi dengan jumlah dokumen yang seharusnya bisa dikenali sistem. Precision adalah jumlah jumlah dokumen yang diklasifikasikan dengan benar oleh sistem dibagi dengan jumlah keseluruhan klasifikasi yang dilakukan oleh sistem. $F$ measure merupakan nilai yang mewakili kinerja 
keseluruhan sistem dan merupakan penggabungan nilai recall dan precision (Aldi, Lailil, \& Indriati, 2013). Berdasarkan Manning, Raghavan, \& Schütze (2008), rumus precission, recall, F-measure, dan akurasi sistem mengacu pada rumus $6,7,8$ dan 9 , sebagai berikut:

Precission $=\frac{\text { true positive }}{\text { true positive }+ \text { false positive }}$

Recall $=\frac{\text { true positive }}{\text { true positive }+ \text { false negative }}$

F-measure $=\frac{2 x \text { precision } x \text { recall }}{\text { precision }+ \text { recall }}$

Akurasi $=$

$\frac{\text { jumlah dokumen benar }}{\text { jumlah seluruh dokumen uji }}$ x 100\%

\section{HASIL DAN PEMBAHASAN}

Data yang digunakan untuk penelitian ini sejumlah 240 buah yang dibagi menjadi 2 bagian yaitu data uji dan data latih. Data tersebut kemudian dibagi kembali dengan porsi data latih yaitu 150 data dan sisanya adalah data uji yaitu sejumlah 90 data. Baik data latih maupun data uji masing-masing dibagi menjadi 3 bagian untuk tiap-tiap kategori emosi yaitu sad, happy dan angry sehingga masing-masing data latih menggunakan data sebesar 50 data dan data uji sebesar 30 data.

Setiap dokumen, baik dokumen latih, uji maupun ISEAR, melewati proses preprocessing, yaitu tokenisasi, stopword dan stemming. Karena data yang digunakan merupakan data berbahasa Inggris, maka proses stemming menggunakan algoritma Porter. Setelah preprocessing dilakukan, dokumen latih masih melalui banyak proses yaitu feature selection dan klasifikasi. Feature selection dilakukan dengan menghitung bobot TF-IDF pada masing-masing term pada tiap dokumen. Jika terdapat pada ISEAR, maka bobot token dikalikan dengan konstanta 10 agar lebih dominan sehingga term tersebut dapat digunakan sebagai kueri dalam mendapatkan penciri dari suatu kategori. Selanjutnya data uji yang sudah dipreprocessing dievaluasi dengan menggunakan rumus akurasi, precision, recall dan $f$-measure. Pada penelitian ini, penulis membangun sistem dengan menggunakan framework CodeIgniter. Tampilan dari program dapat dilihat pada Gambar 2.

Rancangan pengujian dibagi menjadi 2 bagian yaitu pengujian data baik menggunakan feature set ISEAR maupun tidak menggunakan feature set ISEAR. Keduanya menggunakan prosentase feature set ISEAR yaitu sebesar 10\%, - 100\% dengan range 10 tiap prosentase. Hasil pengujian dengan menggunakan ISEAR dapat dilihat pada Tabel 1.

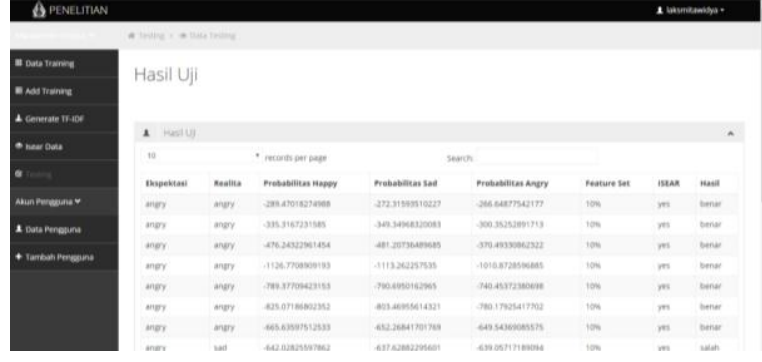

Gambar 2. Tampilan Hasil Uji Sistem

Tabel 1. Hasil Pengujian Menggunakan ISEAR

\begin{tabular}{cccccc}
\hline \multicolumn{2}{c}{ Feature Set } & Precision & Recall & F-Measure & Akurasi \\
\hline \multirow{2}{*}{$10 \%$} & Happy & 0.8667 & 0.9286 & 0.8966 & \multirow{2}{*}{$70 \%$} \\
& Sad & 0.9333 & 0.5385 & 0.6829 & \\
& Angry & 0.3 & 0.9 & 0.45 & \\
\hline \multirow{2}{*}{$30 \%$} & Happy & 0.7667 & 1 & 0.8680 & $73.86 \%$ \\
& Sad & 1 & 0.5660 & 0.7229 & \\
& Angry & 0.4285 & 1 & 0.6 & \\
\hline \multirow{2}{*}{$60 \%$} & Happy & 0.7667 & 1 & 0.8680 & \\
& Sad & 1 & 0.6521 & 0.7894 & $82.2 \%$ \\
& Angry & 0.7 & 1 & 0.8236 & \\
\hline \multirow{5}{*}{$100 \%$} & Happy & 0.7667 & 1 & 0.8680 & \multirow{2}{*}{$82.2 \%$} \\
& Sad & 1 & 0.6521 & 0.7894 & \\
& Angry & 0.7 & 1 & 0.8236 & \\
\hline
\end{tabular}

Sedangkan hasil pengujian tanpa menggunakan ISEAR dapat dilihat pada Tabel 2.

Tabel 2. Hasil Pengujian tidak Menggunakan ISEAR

\begin{tabular}{cccccc}
\hline \multicolumn{2}{c}{ Feature Set } & Precision & Recall & F-Measure & Akurasi \\
\hline \multirow{2}{*}{$10 \%$} & Happy & 0.8667 & 0.9286 & 0.8966 & $70 \%$ \\
& Sad & 0.9333 & 0.5385 & 0.6829 & \\
& Angry & 0.3 & 0.9 & 0.45 & \\
\hline \multirow{2}{*}{$30 \%$} & Happy & 0.7667 & 1 & 0.8680 & $73.86 \%$ \\
& Sad & 1 & 0.5660 & 0.7229 & \\
& Angry & 0.4285 & 1 & 0.6 & \\
\hline \multirow{6}{*}{$60 \%$} & Happy & 0.7667 & 1 & 0.8680 & \\
& Sad & 1 & 0.6521 & 0.7894 & $82.2 \%$ \\
& Angry & 0.7 & 1 & 0.8236 & \\
\hline \multirow{5}{*}{$100 \%$} & Happy & 0.7667 & 1 & 0.8680 & \multirow{2}{*}{$82.2 \%$} \\
& Sad & 1 & 0.6521 & 0.7894 & \\
& Angry & 0.7 & 1 & 0.8236 & \\
\hline
\end{tabular}

Dengan hasil yang didapatkan seperti diatas, grafik Hasil F-Measure pengujian dengan menggunakan ISEAR dipaparkan pada Gambar 2.

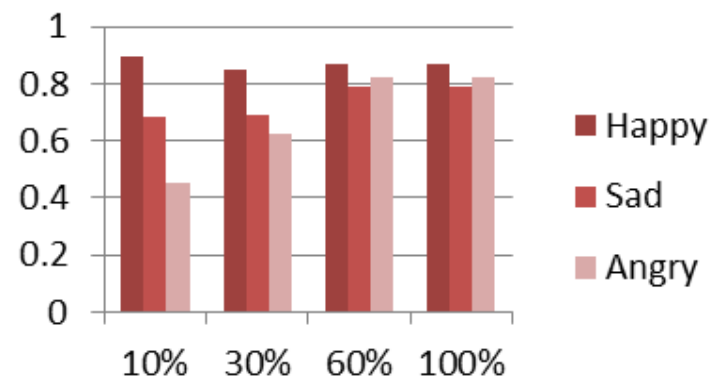

Gambar 2. Grafik pengujian F-Measure Menggunakan ISEAR 
Sedangkan grafik F-Measure tanpa menggunakan ISEAR dapat dilihat pada Gambar 3.

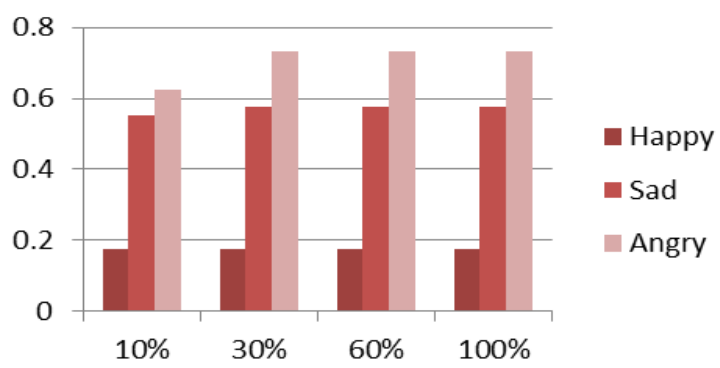

Gambar 3. Grafik pengujian F-Measure tanpa Menggunakan ISEAR

Sehingga rangkuman dari rata-rata precision, recall dan f-measure pada penelitian yang dilakukan dipaparkan pada Tabel 3.

Tabel 3. Hasil Rata-rata F-Measure, Precision, dan Recall

\begin{tabular}{cccc}
\hline Kategori & $\begin{array}{c}\text { Rata-rata } \\
\text { Precision }\end{array}$ & $\begin{array}{c}\text { Rata-rata } \\
\text { Recall }\end{array}$ & $\begin{array}{c}\text { Rata-rata } \\
\text { F-Measure }\end{array}$ \\
\hline Happy & 0.445833333 & 0.860863095 & 0.523766873 \\
Sad & 0.933333333 & 0.506814099 & 0.653457111 \\
Angry & 0.570833333 & 0.90719697 & 0.726655534 \\
\hline
\end{tabular}

Akurasi sistem dari hasil tabel 1 dan 2 dapat dilihat pada Gambar 4 dengan menggunakan ISEAR dan Gambar 5 tanpa menggunakan ISEAR.

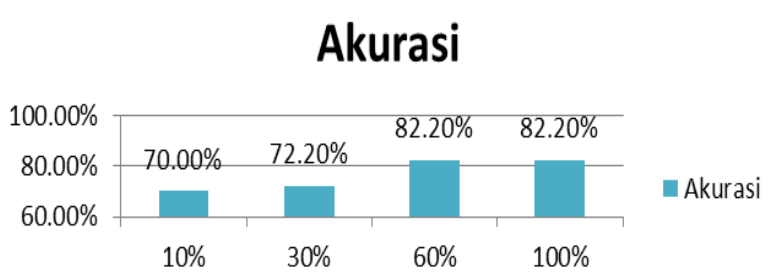

Gambar 4. Grafik Akurasi menggunakan ISEAR

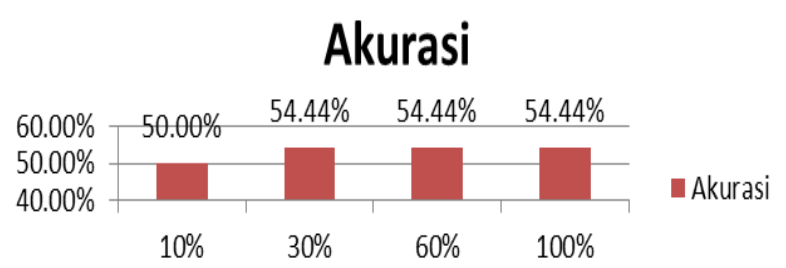

Gambar 5. Grafik Pengujian tidak Menggunakan ISEAR

Pada sistem yang sudah dibangun, hasil dari evaluasi menunjukkan bahwa antara kategori happy dan angry cenderung dikenali sebagai kategori sad sehingga sering mengalami kesalahan dalam klasifikasi. Pada Tabel 3 diatas, nilai precision pada kategori sad sangat tinggi namun recall yang dihasilkan sangat rendah. Rata-rata $f$-meassure tertinggi terdapat pada kategori angry karena baik recall maupun precision memiliki nilai rata-rata yang seimbang.
Dari grafik pengujian yang dihasilkan pada Gambar 4 dan 5, penggunaan feature selection dengan bantuan ISEAR berperan penting dalam peningkatan akurasi. Penggunaan pada sistem ini berguna untuk menunjukkan tingkat kepentingan suatu token yang menjadi penciri suatu emosi tertentu. Semakin tinggi nilai tf-idf dari suatu token, semakin optimum token yang dihasilkan. Penggunaan ISEAR tersebut sangat mempengaruhi hasil dari akurasi. Penggunaan ISEAR memiliki akurasi lebih tinggi dibandingkan tanpa penggunaan ISEAR.

Untuk mengetahui tingkat akurasi sistem, pemilihan porsi feature set yang beragam juga diperlukan untuk menguji apakah penggunaan feature selection dengan bantuan ISEAR berpengaruh terhadap hasil. Hal itu dilakukan dengan menguji dalam beberapa porsi featureset yaitu 10\%, 30\%, 60\% maupun $100 \%$. Proses tersebut dilakukan saat melakukan klasifikasi dokumen. Proses klasifikasi merujuk pada tabel tokentraining yang berisi sekumpulan token yang sudah diberi bobot kemudian di-sort berdasarkan limit porsi featureset yang diinginkan. Dari pengujian yang dilakukan, semakin tinggi pemilihan featureset, hasil akurasi yang dihasilkan semakin besar.

Evaluasi dilakukan setelah dilakukan pengujian terhadap dokumen testing, dengan menghitung nilai peluang dengan menggunakan persamaan 3 . Setelah pengujian dilakukan hasil nilai peluang dokumen banyak direpresentasikan sebagai nilai nol pada bahasa pemrograman PHP karena variable penampung pada PHP memiliki limit pada batas angka tertentu. Untuk mengatasi hal tersebut, penulis menggunakan metode Naïve Bayes dengan memodifikasi logaritma pada bagian choosing class sehingga sangat membantu memperbaiki angka peluang menjadi lebih baik.

\section{KESIMPULAN}

Berdasarkan implementasi dan analisis sistem, maka diperoleh kesimpulan sebagai berikut:

1. Algoritma klasifikasi Naïve Bayes pada penelitian ini tidak dapat menunjukkan hubungan semantik makna emosi antar kata namun ditunjukkan pada probabilitas statistik term antar kata.

2. Proses klasifikasi sering mengalami kesalahan klasifikasi karena 1 lirik lagu memiliki kemungkinan lebih dari 1 emosi yang berbeda.

3. Implementasi Algoritma Naïve Bayes dengan menggunakan ISEAR memberikan akurasi tertinggi pada feature set $60 \%$ dan $100 \%$ sebesar $82,2 \%$. Penggunaan featureset $60 \%$ menggunakan ISEAR sudah cukup untuk menghasilkan nilai akurasi paling maksimal.

4. Berdasarkan hasil pengujian, penggunaaan ISEAR dan peningkatan porsi featureset menghasilkan akurasi yang cukup tinggi. Perbedaan signifikan 
dihasilkan pada penggunaan ISEAR, akurasi ratarata keseluruhan porsi featureset sebesar $77 \%$ sedangkan tanpa menggunakan ISEAR rata-rata akurasi sebesar 53\%. Dokumen paling relevan terdapat pada kategori angry dengan rata-rata precision sebesar 0.57083 , rata-rata recall sebesar 0.9071 dan rata-rata F-Measure sebesar 0.7267.

Saran yang diajukan penulis untuk perbaikan dan pengembangan sistem selanjutnya adalah sebagai berikut:

1. Memodifikasi proses klasifikasi dengan melakukan uji hipotesis dengan perhitungan statistik sehingga sistem dapat mengenali lebih dari 1 kategori emosi agar akurasi meningkat.

2. Memodifikasi algoritma preprocessing yang lebih baik (contoh modifikasi stopword tidak senang menjadi 1 kalimat) pada data latih mapun data training.

3. Menambah dokumen training yang baik sehingga menghasilkan lebih banyak penciri dokumen sesuai kategori yang diharapkan.

\section{DAFTAR PUSTAKA}

[1]. Aldi, S.;Lailil, M.;\& Indriati. (2013). Klasifikasi Berita Bahasa Inggris Menggunakan Algoritma K-Nearest Neighbour (KNN) berbasis Ontologi.
[2]. Destuardi, I.;\& Sumpeno, S. (2009). Klasifikasi Emosi Untuk Teks Bahasa Indonesia Menggunakan Metode Naive Bayes. Seminar Nasional Pascasarjana IX.

[3]. Hamzah, A. (2012). Klasifikasi Teks dengan Naive Bayes (NBC) untuk Pengelompokan Teks Berita dan Abstract Akademis. Prosiding Seminar Nasional Aplikasi Sains \& Teknologi (SNAST) Periode III, B-220 - B-277.

[4]. Lerik, M. D.;\& Prawitasari, J. E. (2005). Pengaruh Terapi Musik terhadap Depresi. SOSIOSAINS, 211.

[5]. Manning, C. D.;Raghavan, P.;\& Schütze, H. (2008). Introduction to Information Retrieval. Cambridge University Press.

[6]. Oatley, K.;\& Jenkins, J. M. (1996). Understanding Emotions. Blackwell.

[7]. Sakti, S. (2010). Eksperimen Mengenai Emosi Oleh Musik Bahagia Dan Sedih Dengan Volume Tertentu. Noudettu osoitteesta Undergraduated Thesis: www.library.usd.ac.id

[8]. Scherer, K. R.;\& Wallbott, H. (1986). How universal and specific is emotional experience? . Social Science Information, 763-795.

[9]. Tala, F. Z. (1999). A Study of Stemming Effects on Information. Noudettu osoitteesta https://www. illc.uva.n1/Research/Publications/Reports/MoL2003-02.text.pdf 